\title{
How effective is an integrated approach to low vision rehabilitation? Two year follow up results from south Devon
}

\author{
G N Shuttleworth, A Dunlop, J K Collins, C R H James
}

\begin{abstract}
Aims-A survey was undertaken to assess the effectiveness of an integrated approach to the provision of low visual aids (LVAs) in south Devon over a 2 year follow up period. This integrated approach includes the assessment of patient needs by low vision therapists, followed by the provision of suitable LVAs, with particular emphasis on training in their use.

Methods-A total of 125 patients were selected at random from the $\mathbf{4 4 5}$ patients seen in the low vision clinic at Torbay Hospital in the year 1991. These patients were sent questionnaires relating to the service over a 2 year period. Questionnaires from 111 patients were analysed at 1 year and 75 questionnaires together with 46 clinical reassessments, after 2 years.

Results-Using a similar questionnaire to one used in a previous study in the UK from a unit where LVA training was not provided, not only was a higher rate of satisfaction found with the services provided, but also the LVAs dispensed were used more frequently. The majority of the LVAs provided were of the simple, inexpensive variety and wastage was very low. Conclusions-It was concluded that this integrated approach to low vision rehabilitation with emphasis on training in the use of less complex LVAs exceeds the performance of other types of service that rely on the dispensing of more complex LVAs.
\end{abstract}

(Br f Ophthalmol 1995; 79: 719-723)

In recent years there has been considerable interest in new approaches to providing low vision rehabilitation. This stems partly from the ever increasing numbers of elderly patients with poor vision, and partly from an awareness of the limitations of more traditional low vision services. ${ }^{12}$

As the proportion of the elderly population increases, so does the number of people with macular degenerative disease, and it is this group that forms the majority of patients requiring low vision services. Age-related macular degeneration (ARMD) was the major factor accounting for the $61 \%$ increase in blindness registrations from 1965 to 1985 in Leicestershire, ${ }^{3}$ and Leat and Rumney have shown that $48 \%$ of all presentations to their low vision clinic were due to ARMD. ${ }^{4}$ The disability that results is most troublesome for near tasks ${ }^{5}$ and the most common request of those suffering from ARMD is to regain the ability to read. ${ }^{7}$

In addition to their visual impairments, elderly people are likely to suffer from an increasing number of other disabilities and frailties that affect their ability to cope with both everyday life and adaptation to various aids, be they visual or otherwise. Particularly relevant for low visual aid (LVA) use is limited dexterity, and difficulty maintaining posture and position during reading. Increasing age and the late onset of visual loss have been shown to hinder the adaptation to, and use of, LVAs. ${ }^{128}$ Other factors that influence compliance with LVA usage are motivation, attitude, cosmesis, and educational background. It has been consistently shown that the elderly will elect to use simple visual aids such as hand held or stand magnifiers, in preference to more complicated devices. ${ }^{1457}$

Traditionally, low vision assessment has been a function of optometrists, either working independently or employed by hospitals. Their practice has generally concentrated upon the provision of optical aids, many of which tend to be spectacle mounted or telescopic, with relatively little time being available for education and training in the techniques required to obtain best use of these aids. Results are generally not very satisfactory; only $23 \%$ of patients prescribed LVAs in Humphry and Thompson's review found them useful at home, 1 and $33 \%$ of patients in McIlwaine et al's survey reported never using the aids provided. ${ }^{2}$

Encouraging results have been obtained in Scandinavia using an integrated approach to low vision rehabilitation which includes both counselling and training in the use of LVAs. ${ }^{59}$ In a series in Finland, reported by Virtanen and Laatikainen, visually handicapped patients were assessed by an ophthalmologist, an optician, and a LVA teacher. ${ }^{5}$ The aids dispensed were not necessarily those that gave maximum visual acuity, but the results were 
impressive with $91 \%$ of patients regaining the ability to read newsprint; the majority preferred simple LVAs. In Sweden, Nilsson and Nilsson demonstrated that for patients with severe ARMD, low vision training enabled $80 \%$ of patients to retain the ability to read newsprint 5 years later. ${ }^{9}$

In this study we have attempted to demonstrate the effectiveness of the integrated low vision rehabilitation programme in operation in south Devon by conducting a postal survey, followed wherever possible by formal reassessment of patients seen by the low vision service over a 2 year period. We consider a successful outcome to be one in which patients are both functionally improved in their own environment and feel that the service has provided adequately for their needs.

\section{Patients and methods}

DESCRIPTION OF THE SERVICE

Since 1986, the South Devon Low Vision Service funded and provided by Torbay Hospital has been run by the Partially Sighted Society, a registered charity. The low vision therapists are qualified orthoptists who have undergone 3 months of additional specialised training in low vision rehabilitation. Patients were referred to the low vision clinic by an ophthalmologist after first having been assessed to exclude treatable conditions and refracted. In addition to prescribing and supplying various LVAs, the low vision therapist (i) carries out a functional assessment of the patient's visual needs, (ii) gives counselling on the nature and consequences of the particular visual impairment, (iii) gives advice and, where necessary, training in the use of LVAs including eccentric fixation techniques, steady eye strategies and focusing, tracking, and scanning skills, (iv) gives information and advice about lighting, and non-optical LVAs; and finally, (v) when appropriate, the therapist also contacts social services and other agencies, on the patient's behalf.

During the assessment, patients are encouraged to try various types of aids, and the most appropriate device is dispensed on a loan basis. The initial appointment lasts for approximately 1 hour. Follow up appointments as deemed necessary by the therapist or at the request of the patient are usually 20 minutes in duration. Patients in the survey were seen in the LVA clinic on average $2 \cdot 2$ times, the average cumulative time spent with the therapist therefore being 84 minutes.

METHOD OF SURVEY AND ANALYSIS

In June 1992 a questionnaire was posted to $125(28 \%)$ of the 445 patients who had attended the Low Vision Clinic at Torbay Hospital during the calendar year 1991. Patients were selected randomly from computer records. The criteria used for selection were (i) the patients had been prescribed a LVA and (ii) they were not waiting for a follow up appointment.
The questionnaire print size was approximately N24. For the purpose of comparison with other low vision services, it included the same questions as those asked by Mcllwaine et al in Glasgow ${ }^{2}$ (see Appendix). Patients who had not returned their questionnaire within 4 weeks, or those with ambiguous responses, were contacted by telephone. Each patient's age, sex, diagnosis, visual acuities, assessment, and training details were then gathered from hospital records.

One year after the initial questionnaire, the respondents were again surveyed to analyse their ongoing satisfaction and LVA usage rate, using the same questionnaire. In addition, wherever possible, patients were objectively reassessed in the low vision clinic where visual acuity, reading speed, and use of specific reading techniques were recorded. If visual acuity had fallen by two Snellen lines or more, patients were reviewed by an ophthalmologist.

In order to provide some degree of statistical comparison between the data collected from the integrated service in south Devon and the data collected from the more conventional service described by McIlwaine et $a l^{2} \chi^{2}$ analysis was performed.

\section{Results}

Of the initial 125 questionnaires at 1 year (1992), a total of 111 were completed (89\%); 104 responses were returned and seven questionnaires were completed by phone. Of the remaining 14 recipients, one had died, two were unable to complete the questionnaire owing to senile dementia, and 11 could not be contacted.

At the 2 year (1993) follow up, 75 of the above 111 patients were able to complete the questionnaire $(68 \%) ; 29$ by telephone. Forty six of these patients agreed to be reviewed in the clinic. Of the remaining non-completed questionnaires, it was found that eight patients had died, six had developed senile dementia, and a further 22 could not be contacted.

In the initial sample, the age range of respondents was 26-99 years, with a mean of 76 years

Table 1 Aetiology of low vision in the 111 respondents at 1 year

\begin{tabular}{lcc}
\hline Diagnosis & Number & Percentage \\
\hline ARMD (alone) & 52 & 47 \\
Multifactorial (including ARMD) & 37 & 33 \\
Diabetic retinopathy & 6 & $5 \cdot 4$ \\
Glaucoma & 4 & $3 \cdot 6$ \\
Hemianopia & 4 & $3 \cdot 6$ \\
Degenerative myopia & 3 & $2 \cdot 7$ \\
Retinal detachment & 2 & $1 \cdot 8$ \\
Albino/nystagmus & 2 & $1 \cdot 8$ \\
Optic atrophy & 1 & $0 \cdot 9$ \\
\hline
\end{tabular}

ARMD = age-related macular degeneration

Table 2 The types of low visual aids prescribed initially

\begin{tabular}{lll}
\hline Type & Number & Percentage \\
\hline Hand magnifier & 45 & 27 \\
Stand magnifier & 34 & 21 \\
Illuminated magnifier & 26 & 16 \\
Pocket magnifier & 22 & $13 \cdot 8$ \\
Spectacle mounted devices & 14 & $8 \cdot 6$ \\
Hand held monocular & 11 & $6 \cdot 8$ \\
Flat field magnifier & 10 & $6 \cdot 2$ \\
\hline
\end{tabular}


Table 3 Usage rate of low visual aids (\%)

\begin{tabular}{llll}
\hline Rate & South Devon 1992 & South Devon 1993 & Glasgow 1989 \\
\hline >10 per day & $43(39)$ & $33(44)$ & $15(18)$ \\
Between 5-10 per day & $26(23)$ & $21(28)$ & $13(16)$ \\
Between 2-5 per day & $19(17)$ & $12(16)$ & $16(19)$ \\
1-2 per week & $13(12)$ & $6(8)$ & $12(14)$ \\
Never & $10(9)$ & $3(4)$ & $27(33)$ \\
\hline
\end{tabular}

compared with the age range in the Glasgow survey of 13-92 years and an average age of $70 .^{2}$ There were 76 females and 35 males in the group similar to the 64 females and 36 males in Glasgow. ${ }^{2}$ Fifty two (47\%) had ARMD as the single cause of their visual impairment and 37 (33\%) had multiple causes including ARMD. The remaining $22(20 \%)$ had a variety of single causes (see Table 1). This compares with $54 \%$ with macular disease, $24 \%$ with multiple aetiology, and $21 \%$ with a single non-macular cause of visual impairment in Glasgow. ${ }^{2}$

Near visual acuities on referral ranged from worse than N60 to the very occasional N6. A total of 212 LVAs were loaned at the initial evaluation, of which 162 were issued on long term loan. The types of LVA issued on long term loan are set out in Table 2. Levels of magnification used ranged from $1.5 \times$ to $20 \times$ (commercial measurement) with a median of $3 \times$. Using the prescribed LVAs, 92 (83\%) respondents achieved near vision acuities of N5, $16(14 \%)$ achieved N6, and three (3\%) achieved N8. All could, therefore, theoretically read newsprint.

Of the 46 patients who were reviewed in the clinic at the 2 year follow up, seven required a change to a higher magnification LVA. Five had developed a significant reduction in visual acuity since their previous visit (up to 2 years earlier), and on ophthalmic review, each showed progression of ARMD.

In the initial questionnaire at 1 year, 102 of 111 patients $(92 \%)$ stated that the service was 'sufficient to meet their needs' with $77 \%$ commenting favourably on the usefulness of the LVA supplied. Seventy two per cent found the explanation of their visual problem useful, and $53 \%$ indicated that the advice and training in LVA usage was helpful. This level of satisfaction compares favourably with the $55 \%$ of patients satisfied with the Glasgow service. ${ }^{2}$ Of the respondents at the 2 year review all reported satisfaction with the service they received.

In the initial survey only 10 patients $(9 \%)$ stated that they never used their LVAs, compared with 33\% recorded in Glasgow (see Table 3). Two of the patients stated that physical disabilities were the reason for nonuse. The average age of the group of non-users was 82 years, compared with 76 years for the respondent population as a whole.

Table 4 The activities for which the dispensed low visual aids were used (\%)

\begin{tabular}{llc}
\hline Activity & 1992 & 1993 \\
\hline Reading correspondence & $84(83)$ & $51(86)$ \\
Reading newspaper/magazine/book & $74(73)$ & $48(64)$ \\
Writing & $39(39)$ & $19(25)$ \\
Hobbies & $27(27)$ & $12(16)$ \\
Work study & $3(3)$ & $1(1)$ \\
Other activities & $14(14)$ & $4(5)$ \\
\hline
\end{tabular}

At the 2 year review, three further patients, each in their eighties, stated that they never used their LVAs. These three patients displayed the mental, physical, and motivational difficulties typical of the elderly population seen by the low vision therapist in that one had developed senile dementia, one felt 'too old to be bothered', and the third found her illuminated stand magnifier 'too difficult to use'.

The majority of patients used their LVAs for reading and writing (see Table 4 ) at both the 1 and 2 year follow ups.

Eighteen respondents had obtained magnifying aids from other sources. Four had obtained them from opticians, six as presents, three from social service departments, two from general stores, two from chemists, and one from a mail order catalogue. The stated usage rates of the LVAs obtained elsewhere are set out in Table 5, together with a comparison with the responses from the Glasgow study. ${ }^{2}$

Of the 46 patients reviewed in the clinic at the 2 year follow up, 19 had been instructed in specific low vision therapy techniques, including eccentric fixation, 'steady eye strategy' (a technique which encourages patients to scroll the test in front of their eye from right to left, rather than moving their LVA and gaze), and tracking and scanning skills. These individuals were given a timed reading test with standard N10 print $^{10}$ to establish whether the patient had mastered the techniques. Reading speeds ranged from 60 words per minute (wpm) to $150 \mathrm{wpm}$, with a mean of $106 \mathrm{wpm}$. In all cases it was judged by the practitioner that the participants were using the techniques in which they had been instructed.

Statistical analysis revealed a significant difference in LVA usage rate after 1 year between the 111 patients issued with an LVA in Devon and the 83 patients issued with an LVA in Glasgow $^{2}$ (see Table 6) $\left(\chi^{2}=22.38, p<0.001\right)$. There was also a significant difference in patient satisfaction after 1 year expressed by the 111 patients who replied to the questionnaire in Devon (92\%) compared with the 91 respondents in Glasgow $(55 \%)^{2}$ (see Table 7) $\left(\chi^{2}=34.71\right.$ [Yates's correction] $\left.\mathrm{p}<0.001\right)$. However, we realise that any comparisons do not take into account differences between the two survey populations; in particular, only 83 (91\%) of the 91 respondents to the satisfaction question in Glasgow had been given an LVA, in contrast with the $100 \%$ of Torbay patients who replied.

\section{Discussion}

There is a growing demand for low vision rehabilitation. In 1988, there were at least

Table 5 Usage rates of LVAs obtained elsewhere (\%)

\begin{tabular}{lcl}
\hline Rate & South Devon 1992 & Glasgow 1989 \\
\hline >10 per day & $5(28)$ & $5(24)$ \\
Between 5-10 per day & $3(17)$ & $4(19)$ \\
Between 2-5 per day & $8(44)$ & $6(29)$ \\
1-2 per week & $2(11)$ & $4(19)$ \\
Never & 0 & $2(9)$ \\
Total number of patients & 18 & 21 \\
\hline
\end{tabular}


Table $6 \chi^{2}$ for the statistical comparison between the usage rates of low vision aids in south Devon and Glasgow

\begin{tabular}{llllllr}
\hline & $>10 /$ day & $5-10 /$ day & 2-5/day & 1 -2/week & Never & Totals \\
\hline Torbay & 43 & 26 & 19 & 13 & 10 & 111 \\
Glasgow & 15 & 13 & 16 & 12 & 27 & 83 \\
Totals & 58 & 13 & 16 & 12 & 27 & 194 \\
\hline
\end{tabular}

$\chi^{2}=22 \cdot 38(\mathrm{df}=4), \mathrm{p}<0.001$.

125000 people registered as blind, and 79000 registered as partially sighted in England. ${ }^{11}$ In 1991 the RNIB estimated that the total (including those not on the official register) number of blind persons in Britain was about 380000 , and the number of partially sighted persons about $580000 .^{12}$ McIlwaine et al suggested that in order to improve the low vision service, additional patient follow up and training in the use of low vision aids was required, ${ }^{2}$ and Scandinavian series seem to bear this out. ${ }^{59}$ In this study, we have endeavoured to demonstrate that an integrated approach providing a wide choice of low vision aids, combined with training and counselling, has increased both patient satisfaction and function.

Most attenders at low vision clinics tend to be elderly and frail, with limited adaptive capability. Many will suffer from ARMD and are likely to request and benefit most from simple low vision aids for near vision tasks, especially reading correspondence and writing. The mean age of respondents in our initial survey was 76 years. ARMD alone accounted for $47 \%$ of their visual impairment, and in a further $33 \%$, ARMD was present in conjunction with other causes of visual disability. The vast majority of patients used their aids for near vision tasks; $83 \%$ for reading correspondence and $73 \%$ for reading for pleasure (see Table 4 ). For these activities, most patients (64\%) were able to use simple aids such as hand magnifiers, stand magnifiers, or illuminated magnifiers. Only $6.8 \%$ used hand held monoculars and only $8.6 \%$ used spectacle mounted devices. The emphasis on supplying simple LVAs, combined with training in their use is in accord with other studies that have used such an integrated training programme. ${ }^{59}$

The south Devon patient satisfaction rate of $92 \%$ at 1 year exceeds the rate quoted by McIlwaine et al $(55 \%),{ }^{2}$ as does the overall usage rate of the low vision aids provided, $91 \%$ compared with $67 \%$ in their series. All patients could read print of an equivalent size to newsprint (N8) with their LVAs at the initial assessment, as could 44 of the 46 patients reviewed clinically 2 years later. These results are comparable with those obtained using a similar integrated approach in Sweden

Table $7 \quad \chi^{2}$ for the statistical comparison between the level of satisfaction with the low vision services in south Devon and Glasgow

\begin{tabular}{lccc}
\hline & Satisfied & Dissatisfied & Totals \\
\hline Torbay & 102 & 9 & 111 \\
Glasgow & 50 & 41 & 91 \\
Totals & 152 & 50 & 202
\end{tabular}

$\chi^{2}=34 \cdot 71(\mathrm{df}=1) . \mathrm{p}<0 \cdot 001$ Yates's correction.
$92 \cdot 5 \%,{ }^{9}$ and Finland $91 \cdot 4 \% .^{5}$ However, we appreciate that this can be very different from patients admitting to regularly reading the newspaper in their own homes.

Mcllwaine $e t a l^{2}$ estimated that the average cost of the LVAs issued to each of their patients was $£ 38$. In addition to this they estimated that the annual cost of the unused, non-returned LVAs was $£ 8000$ for the 744 attenders in 1988-9, or about $£ 10.75$ per clinic attender. In our study the average LVA cost per patient was $£ 23.15$. We estimated that the annual cost of unused, non-returned LVAs was approximately $£ 150$ for the 445 patients seen in 1991, or about 30 pence per clinic attender. We feel that this very considerable difference is due to the greater patient satisfaction resulting from a service that tends to dispense a higher proportion of simple, less expensive devices, combined with training and counselling techniques.

The staffing costs of the optometrist in the Glasgow study were not included in McIlwaine and colleagues' paper. ${ }^{2}$ We estimated that the average staffing cost for each of our patients in 1991 was $£ 21.80$, making the overall cost for each patient in our survey $£ 44.95$, which (at 1991 prices) compares favourably with the figure of $£ 38$ per patient for LVAs alone (at 1988 prices) in the Glasgow survey.

In conclusion, an integrated approach by low vision therapists can, when measured by patient satisfaction and LVA usage rate, result in a low vision rehabilitation service that is more successful than traditional dispensing services. In these days of increasing financial accountability and patient expectation, assessment and dispensing of simple but effective LVAs, with explanation of their use and realistic goal setting by low vision therapists, must warrant very serious consideration by all providers.

1 Humphry RC, Thompson GM. Low vision aids - evaluation in a general eye department. Trans Ophthalmol Soc UK 1986; 105: 296-303.

2 McIlwaine GG, Bell JA, Dutton GN. Low vision aids - is our service cost effective? Eye 1991; 5: 607-11.

3 Thompson JR, Du L, Rosenthal AR. Recent trends in the registration of blindness and partial sight in Leicestershire. Br f Ophthalmol 1989; 73: 95-9.

4 Leat SJ, Rumney NJ. The experience of a university-based low vision clinic Ophthalmol Physiol Opt 1990; 10: 8-15.

Viow $P$, clinic. Oph 1 Primary success with Virtanen P, Laatikainen L. Primary success with low vision aids in age-related macular degeneration. Arch Ophthalmol

6 Collins JK. Coping with the rising incidence of partial sight. Optometry Today 1987; 27: 772-9.

7 Virtanen P, Laatikainen L. Low-vision aids in age-related macular degeneration. Curr Opin Ophthalmol 1993; 4: 33-5.

8 Temel A. Low vision aids (evaluation of 185 patients). Ophthalmol Physiol Opt 1989; 9: 327-31.

9 Nilsson UL, Nilsson SEG. Rehabilitation of the visually handicapped with advanced macular degeneration. Doc Ophthalmol 1986; 62: 345-67.

10 Inde $\mathrm{K}$, Backman $\mathrm{O}$. Reading test 1 in low vision training. Sweden: Liber Harmonds, 1979: 53-5.

11 Registration of blind and partially sighted persons at 31st March 1988. London: DOH A/F 88/7.

12 Bruce IW, McKennell AC, Walker EC. Blind and partially sighted adults in Britain: the RNIB survey. Vol 1. London: HMSO, 1991.

Appendix The questionnaire - size approximate equivalent of $\mathrm{N} 24$

1 How often do you use the magnifying aid/s supplied? Please tick the appropriate box.

a More than 10 times per day

b Between 5-10 times per day 
c Between 2-5 times per day

d Once or twice a week

e Never use the aid/s

2 What do you use the magnifying aid for?

Please tick the most appropriate box below. If you use the aid for more than one activity please mark the boxes $1,2,3$, etc [ 1 being the main activity, 2 being the second most frequent activity, etc].

a Reading correspondence [letters, bills, etc]

b Reading newspapers, magazines, books, etc

c Writing

d Hobbies. Please specify .......

e For work/study

f Other activities. Please specify ......

3 If you never use the magnifying aid supplied, please give reasons why.

4 Was the low vision service sufficient to meet your needs? YES/NO

IF YES. What was the most helpful aspect of the service? Please tick the most appropriate box below. If you found more than one aspect of the service helpful please mark the boxes $1,2,3$, etc [ 1 being the most helpful, 2 being the second most helpful, etc].

a The particular magnifying aid supplied to you

b The explanation about your visual problem

c Advice/training offered to help you use the magnifier

d Advice on lighting

e Advice on other services

f Other help or advice given. Please state

If the low vision service was not sufficient to meet your needs, what could be improved?

a The particular low vision aid supplied to you

b The explanation given to you about your visual problem c The advice and training offered to help you use the magnifying aid

d Advice on lighting

e Advice on available services

f Other help or advice. Please state

5 Do you use a magnifying aid obtained from elsewhere? YES/NO

6 If yes, how often do you use the magnifying aid obtained elsewhere?

Please tick the most appropriate box.

a More than 10 times per day

b Between 5-10 times per day

c Between 2-5 times per day

d Once or twice a week

e Never used

7 Where did you obtain this magnifying aid? Please tick the most appropriate box.

a Purchased from an optician or other outlet

b Obtained from another hospital low vision clinic

c Given to you as a present

d Another source. Please state ......

8 If you have obtained a magnifying aid from another source, what do you use this magnifying aid for? If you use the aid for more than one activity please mark the boxes $1,2,3$, etc [ 1 being the main activity, 2 being the second most frequent activity, etc].

a Reading correspondence [letters, bills, etc]

b Reading newspapers, magazines, books, etc

c Writing

d Hobbies. Please specify .......

e For work/study

f Other activities. Please specify .......

9 Would you like to make any further comments about the service you received at the low vision clinic? 